\title{
An Analysis of Material Character of Literary Works
}

\author{
Liqing Zhang \\ College of liberal arts, Jinan University, Guangzhou Guangdong, 510632, China \\ Jining Normal University, Wulanchabu Inner Mongolia 012000, China
}

Keywords: Literary works, Character, Material character.

\begin{abstract}
During the long history of develpment, literary works has gain miltiple charaters by faotrs like effect of time ,social and manifestations. This article conduct a brief analysis on the characters of the literary works, focus on the material character of the literary, hope to offer certain support and reference for future study on the literary works.
\end{abstract}

\section{Introduction}

Nowadays, in the process of transition from a planned economy to a socialist market economy, our society experienced a great revolution, and based on great impact of the revolution from the economic field and in the political field, it cause a far-reaching influence in the field of culture and art development. Under the current social background, a correct understanding of the characteristics of literary works, deep exploration to the art production rules, are the only way to further improve our art productivity and promote the sustained and healthy development of China's art industry obtains.

\section{The diversity character of literary works}

From the beginning Of civilization progress, literary works have been in the course of forming and developing, the different historical periods and social backgrounds led to the variety performance in its expression and ideas; therefore the literary works also has diversified characteristics, it is shown in the following aspects;

a). Commodity. The material carriers of literary works generally have a certain value of exchange. Although from the formation of works literary, it belongs to the spiritual level of the product, but any kind of thinking and art are bound to some specific material carrier to be to saves and appropriate communicated. The literary work contain certain commodity, since it has a certain value for its emerged material carrier, the materialized labor in exchange of material carrier will complete the transfer of new products, in a certain extent it make the literary carrying out the rational exchange value with other goods ${ }^{[1]}$ At the same time, all literary works are the coagulation of the artist ,who paid labor value, the additional materialized labor to the material carrier of realizes the unification of its practical and value and value characteristics ,prompted the highlights of its commercial properties correspondingly.

b). Literary work has a certain ideological nature. Although literary works have certain commodity, but it is different from commercial product in common sense, because it is created before the commodity economy and it is a kind of ideology and the nature of the spiritual products. Any piece of literary works is bound the influence of its social background ideology, it is a product that people change social ideology of certain period into arts. Therefore, the subjective tendency of the social ideology and the creator often has certain class and ideological tendency, the different history make it conducting certain positive effect to the changes of the culture and art .

c). Literary works has a strong aesthetic. Aesthetic is also an important characteristic of works literary . in the civilization evolution process, Human tends to consciously participate in social labor, to reformed the society and their own , to appreciate initiative and creativity through the product of their labors in transformation process, and to find the intrinsic power of the aesthetic subject ,finally obtain a spiritual pleasure ${ }^{[2]}$ For literary works, it is produced in people's aesthetic activities, related artists can feel the beauty of things in the production practice; stimulate the corresponding desire of 
artistic creation; create different artistic expression forms by the specific writing of their social cognition, the nature of emotion and own ideal life's; create the true beauty will and the awareness ability of the object; highlight personal essential strength in the creation process of literary works; finally make admirer pleasurable experienced in appreciating literary works and get the spirit of emotional sublimation.

d). Literary works is unique in production and exchange literary .Different from The production and exchange of general material product, the production and the exchange of literary work is a personalized artistic creation process, and due to the differences in personal experience personality and hobbies, ideological cultivation of the artist and their own performance practices the in the creation of works of art will result variety of literary works, every piece of works are demonstration of certain individuality characteristic. literary works And for the exchange process of literary work, the value of works literary is often not fixed, so it cannot be treated as general merchandise and implement ate equivalent exchange rules. So in the study cannot simply equivalent the literary works to the general commodity, but should conduct understandings based on the commodity on the essence of the art, and measure its exchange value in a more accurate way, and to ensure sufficient respect has been given to its spiritual value and artistic connotation the during the actual exchange of literary works.

\section{The material characters of the literary works}

Marxist literary theory research clearly pointed out that works must be prior to the appreciation; works is the prerequisite and basis for literary appreciation; also works with certain material properties; it does not existence for human perception. Therefore, it can be said that the mainly sources for appreciation on the literary works is from the media form of the work and the feelings it generated $^{[3]}$ 。 Meanwhile, in the field of literature and art, the feeling produced by appreciation of the works different from natural feeling ways; in life, the feelings and the formation of specific emotions towards natural things are often passive, but feelings and appreciation of literary works is completely different: the appreciation of emotional attitude and aesthetic tendency of the works existed in the expectation of the work, prior to the primary sensory cause on in appreciation, so the work changed into a entity that will continued to be filled in the appreciation by the appreciate.

As a painting hanging on the wall, its performance can be effected by the area, color and the sounding of the wall, but insulated frame by a frame and separated from its surrounding environment; the world within the frame is completed by coloring and modeling, can cause attract to the viewer's attention by a virtual space limited to attractive .To Sartre's analysis, the literary works specifically refers to a kind of objects that in a dominant position, objectively exists in the society, can offer the environment a certain charm, and need to be examined by the aid of specific way during the process of enjoyment.

While in the actual appreciation process, people's perception system is bounded to a corresponding contact with the specific literary works, it will form a hierarchical spatial boundaries, and conduct more broad extension in certain time and space within the scope of people's perception system. In addition, during this process, the appreciate will tend to ignore other aspects, and focus to some special signee of the works, such as the literary works with color changes, the shape of the structure and rhythm and other factors will arouse special emotional in the appreciation of the spirit of the world; this especial emotional is named by Ingarden pictorially as "initial emotion "in the process of preparing, it is the mood drive the appreciate to complete appreciation of literary works, cut the link between their literary experience and past experience and appreciate the activities from the people's daily life to be separated; and it is endowed with unique properties.

In essence, the carrier of the literary works can not only arouse appreciation in appreciation of “preparing emotion”, but also stimulate preliminary understanding and feelings towards the work, such as in the process of understanding the color, texture or notes and other elements of some works, initial feel will be formed about the conveyed emotion usually of the work, this kind of acquisition feeling is not only from the literary works or the color and shape of material caused by the 
understanding and thinking, but also is derived from the feelings of these colors in works of art represented the artistic emotion, and caused by this feeling of art appreciation ${ }^{[4]}$ Such as appreciation of different feeling between the brisk uneven free poetry composed of small sentences long, heavy sentence, neat rhyme metrical verse and neat rhyme metrical verse composed of loose rhythm, between dark and serious bronze and creamy white marble, the appreciation in the appreciation of literary works generally do not have too much contact, you can through the immediate care of work external material, and produce the preliminary art to appreciate the feelings, roughly the spirit of the connotation of the works and the to convey the emotional understanding and the preliminary understanding of the works of artistic realm. This kind of appreciation, which is based on the work material, is expressed at the physiological level, but it is also the basis for the appreciation of the aesthetic experience and the satisfaction of own aesthetic needs. Santee, in the study pointed out that if the Greek tradition of classic literary works on behalf of pantaloon temple is formed not by marble, crown is not gold production, stars will not shine, the sea quiet will not so silent, then the beauty of art will be impossible. If simple emphasis the works of the material carrier in the literary works and stressed the importance of material carrier in the primary process of people's contact physiological arouse emotions that that it they can stimulus the primary feelings, prior to the appreciation ate of the work, the foundation for more advanced emotion to be derived. Mr. Deso had call the image of the people produced in contact with works literary external material in the process of the media process vivify as "aesthetic reflection", and believed that the reaction has a strong physiological properties. For example when listening to music, some tone will bring the excitement of feeling, and others can make people angry, this is the inevitable link between material of literary works and appreciate and physiological structure of the appreciate, also the existence of foundation for the material properties of literary works, .

The appreciation for the literary works experience is from the material carrier but not limited to it. Ingarden once conducted a deep study on the aesthetic perception of the characteristics based the case study of the famous ancient Greek sculpture "Rhodes Venus", and assumes that in the process of art appreciation if constituting the marble statue literary works as a piece of real stone, then the sensor of the watch concentrate to the marble concentration, and found that many material properties, that the first and most real reflection, are ignored the sense of real stone in the appreciation of works of art, such as stains, rough spots, holes etc. found the , but they do have negative impact on literature and art appreciation of the aesthetic feeling ${ }^{[5]}$ While at the same time, if take this works of art as a real woman, then a sense $f$ regret will be generated for the lost arm, which also effect the appreciate the beauty of the art. Which means appreciating the literary works as a literary works will obtain corresponding aesthetic feeling, ignore certain special properties, found the beauty of the art works and leave the best aesthetic impression. Based on that, the actual appreciation process can quickly construct perception through the media medium of the artistic ,this material based art structure override physical reality in the spiritual realm.

In addition, although all literary works have to be carrier by certain material , but initial perception feel is not simple canvas by paper and wood nor separate lines, structure modeling, but by intergradations of all these elements, That is to say specifically refers to the material and lines on paper or canvas form the color structure, or is composed of stone, carved and shape of body structure. As when watching the performance of dancing, the dancer's body, clothing, background, music and lighting while appreciation is the precondition of art appreciation, but in essence, appreciation is not such simple individual elements, and is a virtual image of art formed by these elements, the virtual image will finish of material is the material properties of the germinal and make art realm has been continuously improved. In the actual appreciation for classical dance "spirit of the peacock", appreciates will ignore the dancers themselves, even ignoring all the elements on the stage, but see a beautiful peacock fairy dancing on the grass from the void. It can be see that, the higher artistic value of the work the easier to allow people enjoy the process and ignore its material characteristics, and to immergence themselves into the virtual aesthetic emotion constructed by the literary work. As Marx said, any significance the subject made to people, is measured by personal limitation of the perception, 
here force ,the spiritual implication and artistic edification and soul rendering of literary works exist in certain material imprints, and influenced by material characteristics.

\section{Conclusion}

In conclusion, literary works with diversified characteristics and its material properties exist has had a fundamental impact on the works of spiritual wishes, rendering of the soul and artistic influence effect of ascension, so during the systematic research to the literary works ,the material character of literary works need to attract attention, only fully and clear understanding of its material properties, can guarantee the deepening the research, and enhance the creation of conditions for art appreciation level.

\section{Acknowledgments}

This article is a general projects of 2015 national social sciences fund ,No 15BZW036.

\section{References}

[1] Liu Hongna. On the popularity of network literature and art criticism, Shandong Normal University, 2014.

[2] Yu Songyang, Zhang Xiaomei. The unique nature of the creation of the cross talk "study Lei Feng", Northern music, 2014 (7): 207-207.

[3] Tingting Xie. A study on the cultural characteristics of Saeed and his works, Hunan Normal University, 2013

[4] Rae Jialing. Thoughts on the topic selection of mass literature and art, Literary life - Wenham art gallery, 2013 (12): 254-254274.

[5] Zhang Jingyi. On the characteristics of the new social school in Keigo Higashino's works, Contemporary literary circles, 2014 (4): 92-95. 